\title{
ORIGINAL
}

ARTICLES

\section{Overview and Assessment of a Full-time Family Medicine Faculty Development Fellowship}

Tomoko Sairenji, MD, MS; Jennie B. Jarrett, PharmD, MMedEd; Laura-Mae Baldwin, MD, MPH; Stephen A. Wilson, MD, MPH

BACKGROUND AND OBJECTIVES: Part-time faculty development (FD) fellowships help faculty become successful and effective teachers in medicine. Fulltime FD fellowships provide a unique and promising model to train and retain high-quality faculty. This article presents an overview of a well-established, fulltime FD fellowship at the University of Pittsburgh and the results from a survey of its graduates regarding fellowship experiences and their career trajectories.

METHODS: A 29-item questionnaire was sent to all graduates who completed the University of Pittsburgh St Margaret Faculty Development Fellowship from 1982 and 2014. Questions covered motivation for pursuing the fellowship, explored fellowship experiences, and examined its impact on career and professional development. We present descriptive frequencies and common themes identified from qualitative data from physician respondents.

RESULTS: Fifty-two of the 69 physicians surveyed responded $(75.2 \%$ response rate). Many completed a 2-year fellowship ( $n=32,61.5 \%)$. Nearly two-thirds of graduates had an educator position as their first $(n=34,65.4 \%)$ and current $(n=30,62.5 \%)$ job. Graduates reported a mean fellowship satisfaction score of 8.83 (SD 1.74) on a 10-point scale. Research-related activities and professional development skills were identified as being the most useful/valuable aspects of the fellowship.

CONCLUSIONS: Fellowship graduates were highly satisfied with their training and had a high retention rate in academic positions. Our findings can guide FD fellowship program design and address the needs of future and current educators in medicine.

(Fam Med. 2018;50(4):275-82.)

doi: 10.22454/FamMed.2018.190747

$\mathbf{H}$ ighly skilled and effective faculty members are needed to develop and sustain a robust environment for medical education. The number of full-time faculty in family medicine at US allopathic medical schools has quadrupled from 1980 to $2015 .{ }^{1}$ Changes in Accreditation Council for Graduate Medical

Education (ACGME) requirements have resulted in a medical training paradigm shift from being timebased to competency-based, and now all residencies are required to have a faculty development program. ${ }^{2}$ Consequently, there is a greater need for emphasis on teaching skills (eg, formative feedback, direct observation, curriculum development, assessment and evaluation), leadership, research, and scholarship within family medicine education. Yet many faculty are underprepared for the demands of the job. ${ }^{3}$

Faculty retention is another challenge for academic institutions. An Association of American Medical Colleges analysis found that only $43 \%$ of first-time assistant professors at medical schools remained at the same institution 10 years later. ${ }^{4}$ Faculty development (FD) fellowships may lead to increased longterm retention. ${ }^{5} \mathrm{~A}$ recent study from the University of California, San Diego showed that $67 \%$ of those who completed their FD fellowship program remained as faculty 8 years later compared to $58 \%$ of their counterparts who did not participate in the program. ${ }^{6}$

Most FD fellowships in the United States are offered as part-time programs to early-career faculty members to bolster academic skills..$^{7-10}$ These part-time FD fellowships can have significant personal impact, such as strengthening professional 
identity and increasing confidence as educators. ${ }^{11,12}$ They can also have impact on a larger scale, such as raising peer awareness about scholarly activity and positively changing the research culture within a discipline. ${ }^{9,12-16}$ Considerable research describing and evaluating these programs has amassed over the past 2 decades. ${ }^{17,18}$ In 2010 , half of all US medical schools had part-time FD fellowship opportunities..$^{18}$ Recommendations for creating part-time FD fellowship programs have been published. ${ }^{11}$

However, recently a group of wellestablished, part-time FD fellowship program directors generated constructive advice for future development of FD fellowships. ${ }^{19}$ Competing obligations for part-time fellows such as administrative and clinical duties were believed to impede fellowship training. They suggested that fulltime, postresidency, prefaculty FD fellowships could avoid such barriers. ${ }^{19}$ Based on direct, phone, and email communication with the 27 listed FD fellowships on the AAFP Fellowship Directory, ${ }^{20}$ there are only eight active full-time FD fellowships nationally that emphasize creating educators in family medicine. There is little research evaluating the effects and value of these full-time FD fellowships on careers in education.

\section{Description of the University of Pittsburgh's Full-time Faculty \\ Development Fellowship}

The University of Pittsburgh St Margaret FD fellowship (SM-FD Fellowship) is one of these few full-time FD fellowships. It was established in 1982 at St Margaret Memorial Hospital initially to prepare family physicians to teach primarily in community hospital residency settings. Participants start the program after completion of family medicine residency, and before joining residency or medical school faculty. As medical education changed, the fellowship evolved to meet the needs of medical educators. The mission statement is: "We develop family medicine educators to become master teachers, exemplary clinicians, collaborative researchers, and effective leaders." The curriculum is based on five domains: (1) Teaching and Learning, (2) Professional and Leadership Development, (3) Research and Scholarship, (4) Administration and Management, and (5) Clinical Care. With the increasing need for interprofessional collaboration and leadership, it became an interprofessional fellowship in 2003, where physician fellows and pharmacy residents train together across settings-hospital, outpatient offices, university, classroom, and community.

Physicians self-select into either a 1 or 2-year fellowship; pharmacists participate for 2 years. There was one physician who extended the fellowship to 3 years to pursue more research training. Physician fellows are employed similarly to family medicine residency faculty. They are funded through their teaching and clinical work. They receive a salary equivalent to a PGY-4 and PGY-5 level. Physicians who pursue a 2-year fellowship most often concurrently complete a master of public health (MPH) or master of science in medical education, for which there is partial tuition support. Pharmacy residents are funded through federal graduate medical education funding.

Fellowship structure and didactic activities are shown in Figure 1. Fellows start with an intensive summer seminar series of didactic and small group learning experiences. Subsequently, time is divided approximately as: $20 \%$ structured learning, $40 \%$ clinical and teaching time in the outpatient and hospital setting, 30\% scholarly activity and classwork, and 10\% administration. Approximately $75 \%$ of didactic content occurs in the first year. Most learning and skill development occurs through clinical application and other project experiences. All fellows develop individualized research projects in consultation with fellowship and university faculty. Two-year physician fellows assume advanced junior faculty responsibilities, and are encouraged to integrate fellowship research projects into their additional degree activities. Thus, the additional degree project and fellowship project either are the same or complement each other. Because of this, 2-year fellows are generally more productive and have robust scholarly activity. All fellows attend the Society of Teachers of Family Medicine Annual Spring Conference to gain professional experience and perspective on a national level.

The goal of this study is to describe graduates' experiences of this full-time fellowship, the impact of the FD fellowship in their careers, and examine career trajectories.

\section{Methods}

\section{Questionnaire Development}

The 29-question survey was developed by several of the authors (TS, JBJ, SAW), drawing on questions from existing surveys and interview guides used in studies of FD fellowship graduates. ${ }^{9,12}$ Additional questions that were thought to be particularly relevant to SM-FD fellowship were included. Face validity was established by the family medicine residency and pharmacy residency program directors, then the survey was piloted for relevance, time distribution, flow, and clarity by the FD fellowship classes of 2015 and 2016, and further modified based on feedback. Internal consistency was not measured for question items.

Questions about graduate characteristics were multiple choice. The most useful domain in fellowship was a ranking question ("rank the five domains") with an additional free-text question. Questions on first/ current job titles, motivation for fellowship, influence on career, and aspects that could be improved invited free text responses. Questions on the number of completed scholarly products asked for a numerical response.

\section{Survey Collection}

The survey sampling frame was all physician and pharmacist graduates who completed the FD fellowship 
Figure 1: FD Fellowship Content

EXPERIENTIAL LEARNING

\section{Direct Teaching Experiences Related to Clinical Care}

- Inpatient coattending 4 weeks/year

- Precept physician and pharmacy residents in outpatient clinic 1-3 times/week

- Provide outpatient patient care 1-3 times/week

- Fellow is observed teaching in inpatient and outpatient settings at least once per year

- Group video review of 2 sessions of fellow precepting and 1 lecture/year

- Provision of feedback on student notes $=2$ outpatient notes/month

- OSCE evaluator for UPSOM students 1-3 times/year

- Assist with UPSOP interprofessional clinical exam

- Teach/facilitate at least 1 class/practice-based learning group at UPSOM

\section{Projects and Presentations}

- Complete a project (eg, systematic review, curriculum development, QI, research)

- Present project at interprofessional and interdisciplinary fellowship seminars 1-2 times/year

- Participate and present at STFM Annual Spring Conference

- Complete FPIN Help Desk Answer for publication; clinical inquiry (optional)

- Present at faculty development and research seminar (for residency faculty) 2 times/year

- Present at postgraduate journal club 2 times/year

- Curriculum project (group works together on a 6-hour curriculum for residents)

- Conduct board review for physician residents annually

- Independent lecture of fellow's choice (minimum 1 time/ year)

- Support interprofessional residency medical decision making/journal club sessions (6 times/year)

\section{DIDACTIC LEARNING TOPICS ${ }^{1}$}

\begin{tabular}{|c|c|c|c|c|}
\hline $\begin{array}{l}\text { Teaching and } \\
\text { Learning (40-45\%) } \\
\text { - } \quad \text { Feedback } \\
\text { - } 5 \text { Microskills for } \\
\text { effective clinical } \\
\text { teaching } \\
\text { - } \quad \text { Evaluation (of } \\
\text { learner, of self) } \\
\text { - } \quad \text { Evaluation } \\
\text { frameworks } \\
\text { (competencies, } \\
\text { milestones, and } \\
\text { entrustable } \\
\text { professional } \\
\text { activities) } \\
\text { - Bedside teaching } \\
\text { - Application of } \\
\text { resources }{ }^{2,3} \text { in } \\
\text { teaching and } \\
\text { learning } \\
\text { - Challenging teaching } \\
\text { and learner } \\
\text { encounters } \\
\text { - Curriculum design } \\
\text { - Direct observation } \\
\text { skills } \\
\text { - Video review (of self } \\
\text { and others) } \\
\text { Presentation skills }\end{array}$ & $\begin{array}{l}\text { Professional } \\
\text { and Leadership } \\
\text { Development (25-30\%) } \\
\text { - } \text { Advocacy } \\
\text { - } \text { Body language in } \\
\text { communication } \\
\text { - Imposter syndrome } \\
\text { - } \quad \text { Emotional } \\
\text { intelligence } \\
\text { - Leadership skills } \\
\text { - Media training } \\
\text { - Myers-Briggs type } \\
\text { indicator } \\
\text { - } \text { Professional } \\
\text { - Communication } \\
\text { - Mener letters } \\
\text { - } \text { Emotiong } \\
\text { - } \text { intelligence } \\
\text { Transformative } \\
\text { learning } \\
\text { exercises }\end{array}$ & $\begin{array}{l}\text { Research and } \\
\text { Scholarship (15-20\%) } \\
\text { - } \quad \text { Research topics } \\
\text { (eg, IRB, Intro } \\
\text { to Statistics, } \\
\text { Study Design, } \\
\text { Using Secondary } \\
\text { Databases) } \\
\text { - Journal clubs } \\
\text { - Making academic } \\
\text { - } \quad \text { posters } \\
\text { Peer review } \\
\text { of fellow } \\
\text { presentations } \\
\text { - FPIN peer review } \\
\text { - IRB modules } \\
\text { - Letter to the editor } \\
\text { - Scholarly writing } \\
\text { skills }\end{array}$ & $\begin{array}{l}\text { Administration and } \\
\text { Management (10-15\%) } \\
\text { - } \quad \text { Grant } \\
\text { administration } \\
\text { - } \text { Writing letters of } \\
\text { recommendation } \\
\text { - Negotiation } \\
\text { - } \text { Managing meetings } \\
\text { - } \text { GME funding } \\
\text { - Time management }\end{array}$ & $\begin{array}{l}\text { Clinical Care (10-15\%) } \\
\text { - Bedside teaching } \\
\text { - Information } \\
\text { mastery } \\
\text { (applying } \\
\text { evidence-based } \\
\text { medicine) } \\
\text { - Technology } \\
\text { to improve } \\
\text { teaching and } \\
\text { patient care } \\
\text { - Clinical work } \\
\text { - Individual } \\
\text { interest (eg, } \\
\text { HIV, integrated } \\
\text { medicine) }\end{array}$ \\
\hline
\end{tabular}

${ }^{1}$ Each topic ranged from 1 to 20 hours of didactic time

${ }^{2}$ Medina, J. Brain Rules. Seattle, WA: Pear Press;2008.

${ }^{3}$ Ambrose S, Bridges M, DiPietro M, Lovett C, Norman M. How Learning Works. San Francisco, CA: John Wiley \& Sons; 2010.

*Learning activities that include a reflective component for deep learning; 10/year. eg, 55-word stories, personal mission statement, self-letter of recommendation, Johari window, languages of appreciation, reflective writing.

Abbreviations

FPIN= Family Physicians Inquiries Network

$\mathrm{IRB}=$ Institutional Review Board

OSCE = Objective Structured Clinical Exam

QI= Quality Improvement

STFM= Society of Teachers of Family Medicine

UPSOP $=$ University of Pittsburgh School of Pharmacy

UPSOM= University of Pittsburgh School of Medicine 
between 1982 and 2014. Pharmacist responses were reported separately. ${ }^{21}$ Of the 78 FD fellowship physician graduates, nine were excluded (two deceased, six without valid email addresses, and authors [TS and SAW]). The remaining 69 physicians were surveyed between August and September 2015 using the electronic survey tool Qualtrics. The fellowship coordinator, who is well known to graduates invited them to complete the survey via email, and sent reminders at 2 and 4 weeks. This study protocol was reviewed by Institutional Review Board at the University of Pittsburgh and received exempt status (PRO15060028).

\section{Analysis}

Ordinal and continuous data were analyzed within Qualtrics to produce frequencies, means, and medians. Chi-square test was used to compare first job title by fellow characteristics such as gender, when they completed the fellowship, and fellowship duration. Qualitative assessment of free-text responses on the most useful/valuable area of fellowship, areas of fellowship that could be improved, and impact of fellowship on graduates' careers was done using template analysis method ${ }^{22}$ - organizing and analyzing textual data according to themes, where authors independently identified themes. Common themes within the free text were identified and agreed upon by TS and JBJ. When there was disagreement or ambiguity, resolution occurred via further analysis and discussed with SAW.

Specifically, for free-text responses on job titles, TS, SAW, and JBJ determined categories (clinicians, educators, and administrative leaders) that best described the full scope of all responses, and further divided educators into clinician-educators (eg, clinical faculty such as clinical assistant professor), medical school, and residency faculty. Clinicians were listed as those who did not mention any educational or administrative titles, and were categorized into family physicians, hospitalists, and urgent care physicians. When an individual reported multiple teaching roles, the highest level of teaching engagement was chosen to avoid duplicate counts (eg, residency faculty was chosen if residency faculty and clinical assistant professor were listed).

The most valuable/useful aspects of the fellowship were identified, grouped by theme, and correlated to the five fellowship domains. If a single response had multiple themes, each was counted separately.

\section{Results}

Respondent Characteristics and General Fellowship Experience

Of the 69 physicians, 52 responded ( $75.2 \%$ response rate). Respondent characteristics are shown in Table 1. They identified three main reasons for starting the fellowship: (1) skill attainment ( $n=23,47.9 \%)$, eg: "I wanted to learn a structure and approach to adult education that would help me to teach well"; (2) career development $(\mathrm{n}=17,35.4 \%)$, eg, "To become a program director someday"; and (3) reasons related to lifestyle or convenience $(n=7,14.6 \%)$, eg, "Partly, it was to buy some time while my husband finished his graduate degree, but then it evolved into wanting to be able to teach more effectively and complete MPH."

\section{Employment Following \\ Fellowship}

Nearly two-thirds of fellowship graduates $(\mathrm{n}=34,65.4 \%)$ had a clinicianeducator position as their first job following fellowship (Table 2). Only length of fellowship was significantly associated with a first job being a teaching position with $75.8 \%$ (25/33) of two- or three-year fellowship graduates and $47.4 \%(9 / 19)$ of one-year fellowship graduates becoming educators $(P=0.038$, Table 3$)$. Similar to the first career positions, nearly two-thirds of fellowship graduates had an educator job as their current position (Table 3).

\section{Scholarly Activity Following Fellowship}

The average number of scholarly products per individual over the past 5 years was 17.30 (1.59 peerreviewed publications, 3.78 peer-reviewed presentations, 3.17 reviewer experiences, 1.17 book chapters, 1.56 curriculum development, and 6.02 quality improvement projects).

\section{Satisfaction and Career Utility}

Graduates reported a mean satisfaction score of $8.83(n=48, S D$ 1.74 ) on a 10 -point scale ( $0=$ lowest, $10=$ highest satisfaction). Graduates identified that skills and knowledge attained in fellowship were frequently used in their current work (mean $4.1[\mathrm{n}=48, \mathrm{SD} 0.78]$ on a 5 -point scale [1=never, $5=$ =almost always]).

\section{Most Useful/Valuable Domains of Fellowship}

Of the five structured fellowship domains, graduates ranked "Teaching and Learning" as the most useful domain. However, comments in response to the free-text question "What were the most valuable and/ or useful aspects of fellowship?" suggested that skills and knowledge acquired through research-related activities, such as their fellowship project and biostatistics education were the most useful (22 of 52 respondents). The "Professional and Leadership Development" domain, including elements such as mentorship, time for reflection, career exploration, and networking opportunities were also cited as having significantly contributed to their current careers.

\section{Aspects of Fellowship That Could Be Improved}

Of the 48 graduates who responded to this free-text question, 15 responded that there were no areas in the fellowship that needed improvement. An equal number of fellows responded that content covering negotiation, business proposals, and practice management could be strengthened. Five respondents 
Table 1: SM-FD Fellowship Graduate Survey Respondent Characteristics and Fellowship General Information ( $=52), 2015$

\begin{tabular}{|c|c|c|}
\hline Characteristic & $\mathbf{n}$ & $\%$ \\
\hline Female & 31 & $59.6 \%$ \\
\hline \multicolumn{3}{|l|}{ Graduation Cohort } \\
\hline $1982-91$ & 5 & $9.6 \%$ \\
\hline $1992-2001$ & 17 & $32.7 \%$ \\
\hline $2002-2011$ & 23 & $44.2 \%$ \\
\hline $2012-2014$ & 7 & $13.5 \%$ \\
\hline \multicolumn{3}{|l|}{ Fellowship Length } \\
\hline 1 year & 19 & $36.5 \%$ \\
\hline 2 years & 32 & $61.5 \%$ \\
\hline 3 years & 1 & $1.9 \%$ \\
\hline \multicolumn{3}{|c|}{ Degree/Certificate Pursued Concurrently With Fellowship } \\
\hline Master's degree & 29 & $55.8 \%$ \\
\hline Certificate & 7 & $13.5 \%$ \\
\hline Neither & 16 & $30.8 \%$ \\
\hline \multicolumn{3}{|l|}{ Type of Degree/Certificate } \\
\hline Public health & 26 & $72.2 \%$ \\
\hline Medical education & 4 & $11.1 \%$ \\
\hline Clinical research & 1 & $2.8 \%$ \\
\hline Clinical certificates (HIV, integrative, sports medicine, and global health) & 5 & $13.9 \%$ \\
\hline
\end{tabular}

Table 2: First and Current Job Titles for 2015 Graduates of SM-FD Fellowship

\begin{tabular}{|c|c|c|}
\hline & First Job (n=52) & Current Job (n=48) \\
\hline Educators & $34(65.4 \%)$ & $30(62.5 \%)$ \\
\hline Clinical faculty & 9 & 6 \\
\hline Medical school faculty & 7 & 8 \\
\hline Residency faculty & 14 & 3 \\
\hline Both medical school and residency faculty & 1 & 2 \\
\hline Unspecified faculty & 3 & $8(15.4 \%)$ \\
\hline Administrative leaders* & $2(3.8 \%)$ & $11(22.9 \%)$ \\
\hline Clinicians & $16(30.8 \%)$ & 3 \\
\hline
\end{tabular}

*Examples of titles: Medical Director, Director of Patient Safety and Risk Management

wanted to know more about academic/residency structure, current trends in education, and leadership training.

\section{Fellowship Influence on Current Career}

Qualitative assessment of free-text comments revealed graduates' perceived impact of the FD fellowship on their careers. Frequent themes were that the fellowship provided skill acquisition, opportunities for self-discovery, and improved context to help them make critical career development and path decisions.

Fellows described how teaching skills obtained during fellowship were currently used in their work environment. One graduate wrote,
[My] FD fellowship background helped to fill a need within the residency and department... to train the other junior faculty involved in residency education [to become] better educators. I have also been heavily involved in the development of multiple curricula, evaluation tools, precepting, OSCE for our residents, direct observation, and 
Table 3: 2015 SM-FD Fellowship Graduates' First Job Types by Graduate Characteristics

\begin{tabular}{|l|c|c|c|}
\hline & Educators & $\begin{array}{c}\text { Administrative } \\
\text { Leaders*and Clinician }\end{array}$ & Total \\
\hline Overall & $34(65.4 \%)$ & $18(34.6 \%)$ & 52 \\
\hline Gender & & & $P=0.45$ \\
\hline Female & $19(61.3 \%)$ & $12(38.7 \%)$ & 31 \\
\hline Male & $15(71.4 \%)$ & $6(28.6 \%)$ & 21 \\
\hline FD Fellowship Completion & & & $P=0.881$ \\
\hline Before 2002 & $14(63.6 \%)$ & $8(36.4 \%)$ & 32 \\
\hline 2002 and after & $16(53.3 \%)$ & $10(46.7 \%)$ & $P=0.038$ \\
\hline Duration of Fellowship & & & 19 \\
\hline 1 year & $9(47.4 \%)$ & $8(24.2 \%)$ & 33 \\
\hline 2 or 3 years & $25(75.8 \%)$ & & \\
\hline
\end{tabular}

*Examples of leader titles: Medical Director, Director of Patient Safety and Risk Management

milestone assessment... I think it would have been a lot harder to take on some of these things without my background.

Others agreed that without the fellowship it might have been difficult to pursue their current role. This was true for those who also pursued academic work. One graduate wrote,

\begin{abstract}
"My career path has led me to a place where I get to do a fair amount of academic work in the clinical knowledge management space but in a real delivery system where clinical practice guidelines have an opportunity to be implemented, not simply published. If I hadn't completed the FD fellowship, I can't imagine that I would have followed this career path."
\end{abstract}

Another graduate wrote,

The experience in the FD fellowship allowed me to choose an academic position with a variety of activities, including clinical/academic teaching and research etc, in which I could comfortably keep myself engaged. Without the fellowship training, I would have chosen $100 \%$ clinical work.

Many graduates also described how the fellowship created numerous opportunities for self-discovery and reflection. One graduate summarized this as, "I had the opportunity to discover personal strengths and interests that I hadn't known about."

Another graduate noted, "Without the fellowship training, I wouldn't have even thought of becoming a residency director."

Critical beliefs were developed during the fellowship, and many appreciated mentorship opportunities, both elements aptly expressed, by one graduate as "The mentorship established some core beliefs and values that I think are used daily."

\section{Discussion}

Full-time FD fellowships are an opportunity to learn and master many of the skills that are now required to be highly skilled and effective clinician-educators. In this study, we found that SM-FD fellowship graduates were highly satisfied with the program and felt that skills achieved during fellowship were used often in their current position. Fellows were able to develop and reflect on career goals, and they received mentorship to reach those goals. They often commented that the FD fellowship broadened their horizons as to what was possible for their careers.

There are little general data on the career trajectories of those who complete an FD fellowship. That 78\% of the FD fellowship graduates are in teaching (63\%) and administrative leadership (15\%) positions is consistent with components of the FD fellowship mission to develop teachers and effective leaders. In one study from 1999, $75 \%$ of newly-graduated FD fellows from various programs proceeded into academic positions, but $37 \%$ of these expected to leave their current positions in the next 1 to 2 years, suggesting a high turnover rate. ${ }^{23}$ In this study, graduates of the SM-FD fellowship appreciated the time and space allowed to reflect on career options and to promote self-realization. There is a concept of professional identity formation, critical to the well-being of physicians, that has been extensively explored in the context of medical student education. ${ }^{24,25}$ Through the opportunities for career exploration and reflection, paired with strong mentorship, fellowship graduates formed a stronger sense of professional identity, allowing them to find niches within academia that provided higher levels of satisfaction and retention in education. Comments such as, "Without the fellowship training, I wouldn't have even thought of becoming a residency director," suggest the fellowship provided exposures that broadened thinking about not only career path, but also trajectory. 
Table 4: Comparison of Scholarly Products for St Margaret Family Medicine Residency Faculty, Means Per Individual Over a 3-Year Period, 2014-2017

\begin{tabular}{|l|c|c|}
\hline \multicolumn{1}{|c|}{ Scholarly Work } & $\begin{array}{c}\text { Faculty Who Did Not Complete } \\
\text { the FD Fellowship (n=20) }\end{array}$ & $\begin{array}{c}\text { Faculty Who Completed the } \\
\text { FD Fellowship (n=12) }\end{array}$ \\
\hline Peer-reviewed publications & 0.73 & 4.00 \\
\hline Letter to the editor & 0.05 & 0.33 \\
\hline Peer-reviewed presentations & 7.79 & 0.25 \\
\hline Curriculum resources* & 0.11 & 0.42 \\
\hline Narrative pieces & 0.16 & 0.17 \\
\hline CME video lecture & 0.89 & 0.42 \\
\hline Book chapters & 0.32 & 16.01 \\
\hline Total & 10.06 & 2 \\
\hline
\end{tabular}

*eg, Association of Family Medicine Residency Directors (AFMRD) and Society of Teachers of Family Medicine (STFM) Family Medicine Residency Curriculum Resource

Faculty scholarly activity is necessary for further development of primary care research, and ACGME requires two products over 5 years for residency faculty. ${ }^{26}$ Educators' scholarly activity has a substantial impact on learners and can result in higher ranks for faculty. ${ }^{27}$ In residency programs where faculty members are productive scholastically, residents are productive as well. ${ }^{3,28}$ Conversely, in residency programs that struggle, lack of faculty mentorship is a barrier. ${ }^{29}$ In this study, $42.3 \%$ of graduates specifically noted scholarly activity to be the most useful aspect of the fellowship. Though we could find no published data for comparison, the overall productivity level of graduates appears high, averaging 17.3 products over 5 years, especially considering the aforementioned ACGME requirement. We later performed a curriculum vitae review of UPMC St Margaret Family Medicine Residency faculty for the 2014-2017 period and found that those who had completed the FD fellowship had higher scholarly activity than those who did not (Table 4).

In this study, a significantly higher rate of those who completed 2- or 3 -year of fellowship became faculty compared to those who completed a 1-year fellowship (75.8\% vs $47.4 \%$ ). Possibly, 2 to 3 years of FD fellowship provide better preparation or is an indicator of level of commitment to an academic career. Perhaps those who desire a 2-year fellowship should be selected over 1-year candidates to bolster academicians. However, a 1-year fellowship may be beneficial for those who desire career exploration, particularly one in academic family medicine. It is better for them and their future employers if exploration is done prior to faculty employment.

Outcomes of this FD fellowship transcended health professions, with benefits seen for both physician and pharmacist participants. High satisfaction with the fellowship was also found for the pharmacist cohort, a 9.04 on a 10 -point scale ( $10=$ highest satisfaction). ${ }^{20}$ Additionally, pharmacist graduates also recorded high numbers of clinical teaching positions and in scholarly production. ${ }^{20}$ Unfortunately, this survey did not identify whether the interprofessional nature of the fellowship affected their learning.

The fellows add great value to the affiliated residency programs in terms of their educational, scholarly, and patient care activities. The residency programs enjoy easier recruitment of highly-trained faculty members into their programs. Based on FD fellowship graduate data of 78 physicians who completed the program between 1983 and 2014, 14 remain in Pittsburgh, and 10 more within a 200-mile radius as partand full-time educators.

There were some limitations to our study, including data collection self-report by recall, and some fellows having graduated more than 30 years prior to the survey. The level of detail of free-text responses varied. FD fellowship experience varied over time as the fellowship has intentionally adapted in response to participant feedback and the changing medical education environment.

\section{Conclusion}

This study evaluated the career paths of physician graduates of a 33-year-old, full-time family medicine FD fellowship. Graduates reported high satisfaction with the FD fellowship, a sense that it positively impacted their careers, and success as clinician-educators. Graduates, especially of the 2-year track, had high entrance and retention rates in academic family medicine. Changes in the medical education landscape suggest that faculty can no longer be excellent clinicians who teach, but must become equally educator and clinician - a transition from "Clinician-educator" to "Clinician- $E$ ducator." This successful full-time FD fellowship model may serve to guide future faculty development efforts to prepare Clinician-Educators. 
ACKNOWLEDGMENTS: The authors wish to thank Dr Ted Schaffer, UPMC St Margaret Family Medicine Residency Program Director, and the 2015 and 2016 FD fellowship classes for piloting the survey, Dr Patricia Klatt, UPMC St. Margaret Pharmacy Residency Program Director for contributing background information on the pharmacy residency program and helping with survey development. We are extremely grateful to Mrs Paula Preisach, for her extensive administrative efforts in locating graduates, survey collection, contacting other fellowship programs, and providing internal data on our FD fellowship.

Parts of this study were presented at the 2017 STFM Annual Spring Conference in San Diego, CA, May 5-9, 2017.

CONFLICT DISClosURE: Tomoko Sairenji was a fellow at the time of data collection, and Stephen A. Wilson is the former director of the University of Pittsburgh St Margaret Faculty Development Fellowship.

CORRESPONDING AUTHOR: Address correspondence to Dr Sairenji, E-304, $1959 \mathrm{NE}$ Pacific Street, Seattle, WA 98195-6390. 206543-9425. Fax: 206-543-3821. sairenji@uw.edu.

\section{References}

1. Xierali IM, Nivet MA, Gaglioti AH, Liaw WR, Bazemore AW. Increasing family medicine faculty diversity still lags population trends. J Am Board Fam Med. 2017;30(1):100-103.

2. Accreditation Council for Graduate Medical Education. Program Requirements for Graduate Medical Education in Family Medicine, 2016. http://www.acgme.org/portals/0/pfassets/programrequirements/120_family_medicine_2016.pdf. Accessed February 13, 2018.

3. DeHaven MJ, Wilson GR, O'Connor-Kettlestrings $\mathrm{P}$. Creating a research culture: what we can learn from residencies that are successful in research. Fam Med. 1998;30(7):501-507.

4. Alexander HLG. The long-term retention and attrition U.S. medical school faculty. AAMC Analysis in Brief. 2008;8(4):1-2.

5. Ries A, Wingard D, Morgan C, Farrell E, Letter $\mathrm{S}$, Reznik V. Retention of junior faculty in academic medicine at the University of California, San Diego. Acad Med. 2009;84(1):37-41.

6. Ries A, Wingard D, Gamst A, Larsen C, Farrell E, Reznik V. Measuring faculty retention and success in academic medicine. Acad Med. 2012;87(8):1046-1051.

7. Simpson D, Marcdante K, Morzinski J, et al Fifteen years of aligning faculty development with primary care clinician-educator roles and academic advancement at the Medical College of Wisconsin. Acad Med. 2006;81(11):945-953.
8. Robins L, Ambrozy D, Pinsky LE. Promoting academic excellence through leadership development at the University of Washington: the Teaching Scholars Program. Acad Med. 2006;81(11):979-983.

9. Lown BA, Newman LR, Hatem CJ. The personal and professional impact of a fellowship in medical education. Acad Med. 2009;84(8):10891097.

10. Frohna AZ, Hamstra SJ, Mullan PB, Gruppen $\mathrm{LD}$. Teaching medical education principles and methods to faculty using an active learning approach: the University of Michigan Medical Education Scholars Program. Acad Med. 2006;81(11):975-978.

11. Hatem CJ, Lown BA, Newman LR. Strategies for creating a faculty fellowship in medical education: report of a 10-year experience. Acad Med. 2009;84(8):1098-1103.

12. Woods SE. A qualitative assessment of one cohort from the University of North Carolina Family Medicine Faculty Development Fellowship. Fam Med. 2002;34(2):126-131.

13. Newman LR, Pelletier SR, Lown BA. Measuring the Impact of Longitudinal Faculty Development: A Study of Academic Achievement. Acad Med. 2016;91(12):1676-1683.

14. Bolon SK, Phillips RL Jr. Building the research culture of family medicine with fellowship training. Fam Med. 2010;42(7):481-487.

15. Plack MM, Goldman EF, Wesner M, Manikoth N, Haywood Y. How learning transfers: a study of how graduates of a faculty education fellowship influenced the behaviors and practices of their peers and organizations. Acad Med. 2015;90(3):372-378.

16. Steinert Y, Naismith L, Mann K. Faculty development initiatives designed to promote leadership in medical education. A BEME systematic review: BEME Guide No. 19. Med Teach. 2012;34(6):483-503.

17. Leslie K, Baker L, Egan-Lee E, Esdaile M, Reeves S. Advancing faculty development in medical education: a systematic review. Acad Med. 2013;88(7):1038-1045.

18. Thompson BM, Searle NS, Gruppen LD, Hatem CJ, Nelson EA. A national survey of medical education fellowships. Med Educ Online. 2011;16(1):16.

19. Coates WC, Runde DP, Yarris LM, et al. Creating a Cadre of Fellowship-Trained Medica Educators: A Qualitative Study of Faculty Development Program Leaders' Perspectives and Advice. Acad Med. 2016.

20. American Academy of Family Physicians. AAFP Fellowship Directory. https://nf.aafp. org/Directories/Fellowship/Search. Accessed Sept 10, 2017.
21. Jarrett JB, Sairenji T, Klatt PM, Wilson SA. An innovative, residency-based, interprofessional faculty development program. Am J Health Syst Pharm. 2017 Mar 15;74(6):402-408.

22. The University of Sheffield. Learning and Teaching Services, Template Analysis. 2014; https://www.sheffield.ac.uk/lets/strategy/resources/evaluate/general/data-analysis/template-analysis. Accessed March 3, 2017.

23. Kohrs FP, Mainous AG III. Retention of family medicine faculty development fellows in academic medicine. Fam Med. 1999;31(1):23-27.

24. Wald HS. Professional identity (trans)formation in medical education: reflection, relationship, resilience. Acad Med. 2015;90(6):701-706.

25. Holden MD, Buck E, Luk J, et al. Professional identity formation: creating a longitudinal framework through TIME (Transformation in Medical Education). Acad Med. 2015;90(6):761767.

26. Accreditation Council for Graduate Medical Education. Scholarly Activity Guidelines Review Committee for Family Medicine. 2016; https://www.acgme.org/Portals/0/PFAssets/ ProgramResources/120_scholarly-activityguidelines.pdf. Accessed February 13, 2018.

27. Taylor JS, Friedman RH, Speckman JL, Ash AS, Moskowitz MA, Carr PL. Fellowship training and career outcomes for primary care physician-faculty. Acad Med. 2001;76(4):366-372.

28. Crawford P, Seehusen D. Scholarly activity in family medicine residency programs: a national survey. Fam Med. 2011;43(5):311-317.

29. Bammeke F, Liddy C, Hogel M, Archibald D, Chaar Z, MacLaren R. Family medicine residents' barriers to conducting scholarly work. Can Fam Physician. 2015;61(9):780-787. 